\title{
Adverse Effect Mitigation Study
}

National Cancer Institute

\section{Source}

National Cancer Institute. Adverse Effect Mitigation Study. NCI Thesaurus. Code C49655.

A type of study designed to identify actions necessary to eliminate or reduce the risk to human life or well-being as a result of a particular medication, treatment regimen, procedure, or any other medical intervention. 